\title{
Assessing the Shape of the Viscoplastic Iron-Ore Zone in a Blast Furnace
}

\author{
O. P. Onorin ${ }^{a}$, N. A. Spirin ${ }^{b}$, V. V. Lavrov ${ }^{b}$ I. E. Kosachenko ${ }^{c}$, and V. Yu. Rybolovlev \\ ${ }^{a} \mathrm{OAO}$ Ural'skii Institut Metallov, Yekaterinburg \\ ${ }^{b}$ Yeltsin Ural Federal University, Yekaterinburg \\ ${ }^{c}$ OAO Magnitogorskii Metallurgicheskii Kombinat (MMK)
}

Received January 22, 2013

\begin{abstract}
A mathematical model permits assessment of the position and shape of the viscoplastic iron-ore zone (cohesion zone) in a blast furnace and identification of a rational configuration for this zone on the basis of readily available information regarding the blast furnace in the baseline period. The model also permits the solution of design problems with variation in the furnace parameters. Modeling results are outlined for the baseline and design periods.
\end{abstract}

Keywords: blast furnaces, mathematical modeling, heat transfer, viscoplastic conditions, iron ore, cohesionzone configuration

DOI: $10.3103 / \mathrm{S} 0967091213060132$

According to current concepts, the gas permeability of the batch column in a blast furnace is determined by the position and shape of the viscoplastic zone (cohesion zone), above which the batch consists of solid pieces and below which hot metal and slag melt drain through the coke bed. The viscoplastic zone consists of alternating layers of iron ore and coke. The presence of the coke layers (coke windows) ensures gas permeability; the viscoplastic iron-ore layers are impermeable. The presence of coke windows is confirmed by studies in frozen blast furnaces. Indirect evi- dence of their importance is that, if premixed ore and coke are charged in the blast furnace, leading to destruction of the coke windows, the gas-dynamic drag of the cohesion zones increases, while the furnace productivity declines by a factor greater than 1.85.

In Fig. 1, we show possible shapes of the viscoplastic zone, together with the permeating gas fluxes [1-3].

For high furnace productivity and low coke consumption, the narrow inverted- $U$ configuration is the best (Fig. 1). This configuration is also associated with long life of the furnace's refractory lining. In all other (a)

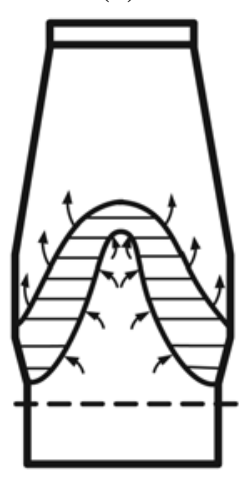

(b)

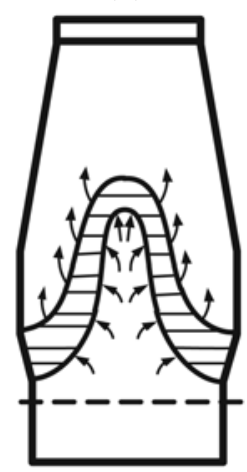

(c)

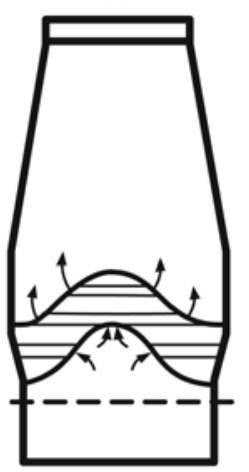

(d)

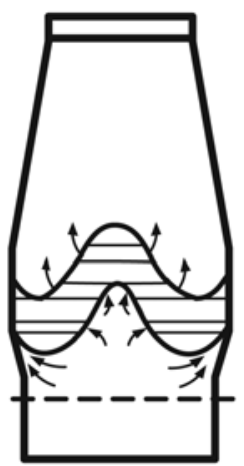

Fig. 1. Possible shapes of the viscoplastic zone and gas fluxes in a blast furnace: (a) inverted-U configuration, with a large number of coke windows; (b) narrow inverted-U configuration; (c) horizontal zone; (d) W-shaped zone. 
cases, the furnace performance is poorer, either because of the small number of coke windows and the consequent low permeability of the cohesion zone, which limits the supply of blast to the furnace; or on account of the proximity of the furnace lining to the hot gases leaving the viscoplastic zone. The position and shape of the viscoplastic zone in the blast furnace depends on factors such as the ore distribution over the cross section and the characteristics of the viscoplastic iron ore: the initial softening temperature and the fluidization temperature (corresponding to the appearance of fluid slag). The maximum productivity corresponds to optimal configuration of the viscoplastic zone, minimum thickness of that zone, and the best melt filtration into the lower level.

Despite the resources available for determining the position of the viscoplastic zone in the blast furnaceincluding mathematical modeling [4-13]-it is important to develop ongoing monitoring of its position and to assess its motion in the course of smelting.

Mathematical models of the blast furnace are based on the principle of perturbed-unperturbed motion [14]. The model may be divided into two parts: the model of the baseline state; and a predictive model. The model of the baseline state permits assessment of the state of the process from mean values over the baseline period. The predictive model permits assessment of the blast-furnace characteristics with change in the conditions, on the basis of the results from the model of the baseline state $[15,16]$. In developing this model, attention focused on the thermal, blast, gasdynamic, and slag parameters and the nonuniform distribution of the gas and materials. It does not give due attention to the viscoplastic zone. In Fig. 2, we show the structure of the subsystem for modeling the position and configuration of the viscoplastic iron-ore zone.

In the baseline period, we solve several successive problems.

(1) Determining the ore distribution over the cross section. We use the model data for charging in a nonconical system. For conical charging systems, an indirect approach is adopted, on the basis of the carbondioxide distribution or the temperature distribution in the cross section. It is assumed that the ore distribution is proportional to the carbon-dioxide distribution and inversely proportional to the temperature distribution.

(2) Determining the gas velocity and flow rate in annular cross sections of the bosh and mouth. From measurements of the upper and lower pressure differences and the ore distribution, we calculate the mass and volume ratio of the iron ore and coke, the suspension of the batch by gas, and the gas velocity and flow rate in annular cross sections of the furnace mouth. The filtration rate of the gas in annular cross sections of the shaft is calculated by means of the Egon equa- tion relating the drag of the batch layer to the batch and gas parameters. The following parameters are calculated: the coke and ore volume in the annular cross sections; the porosity of the batch layer in each annular cross section of the cohesion zone and the melt-filtration zone; the gas velocity in the selected bosh cross section; the bulk flow rate of the gas passing through the annular cross sections to the moth; the yield of tuyere gas; and the mean gas filtration rate in the bosh region. As the batch moves from the furnace mouth to the tuyere zones, the size of the batch pieces is reduced. The size of the coke pieces reaching the tuyeres is reduced by a factor of 1.14-1.40, depending on the fractional composition of the coke charge.

(3) Calculating the thickness of the coke windows in the bosh region; the filling of the coke packing with slag; the porosity of the coke charge and the cohesion zone; the yield, composition, and properties of the primary slag; and their distribution over the furnace radius. The thickness of the coke windows in the bosh region is determined from the coke volume in the given vertical cross section of the bosh and the crosssectional area of the bosh core.

(4) Calculating the heat transfer in the upper and lower zones of the blast furnace. By specifying the thermal characteristics of the batch components, the parameters determining the heat transfer in both the upper and lower zones may be determined, with calculation of the batch and gas temperature in the lower heat-transfer stage over the annular cross sections.

(5) Determining the viscoplastic characteristics of the ore: the initial softening temperature and the fluidization temperature (corresponding to the appearance of fluid slag). If experimental data regarding the viscoplastic characteristics of the ore are available, they may be used in the model, in place of the calculation results.

(6) Determining the position and configuration of the viscoplastic zone. By using the model for the viscoplastic zone in terms of the temperature fields of the batch in the annular cross sections at the bottom of the furnace, isotherms corresponding to the initial softening temperature and the melting range of the ore may be found. From the results, the position and configuration of the viscoplastic zone is determined in the furnace profile for the baseline period.

(7) Diagnostics of the rational configuration and height of the viscoplastic zone (cohesion zone).

In the prediction phase, the following options are available.

(1) Introducing changes in the smelting parameters: the composition and properties of the iron ore, the charging conditions, the radial ore distribution, the blast parameters (temperature, moisture content, oxygen content, natural gas consumption), the filter- 


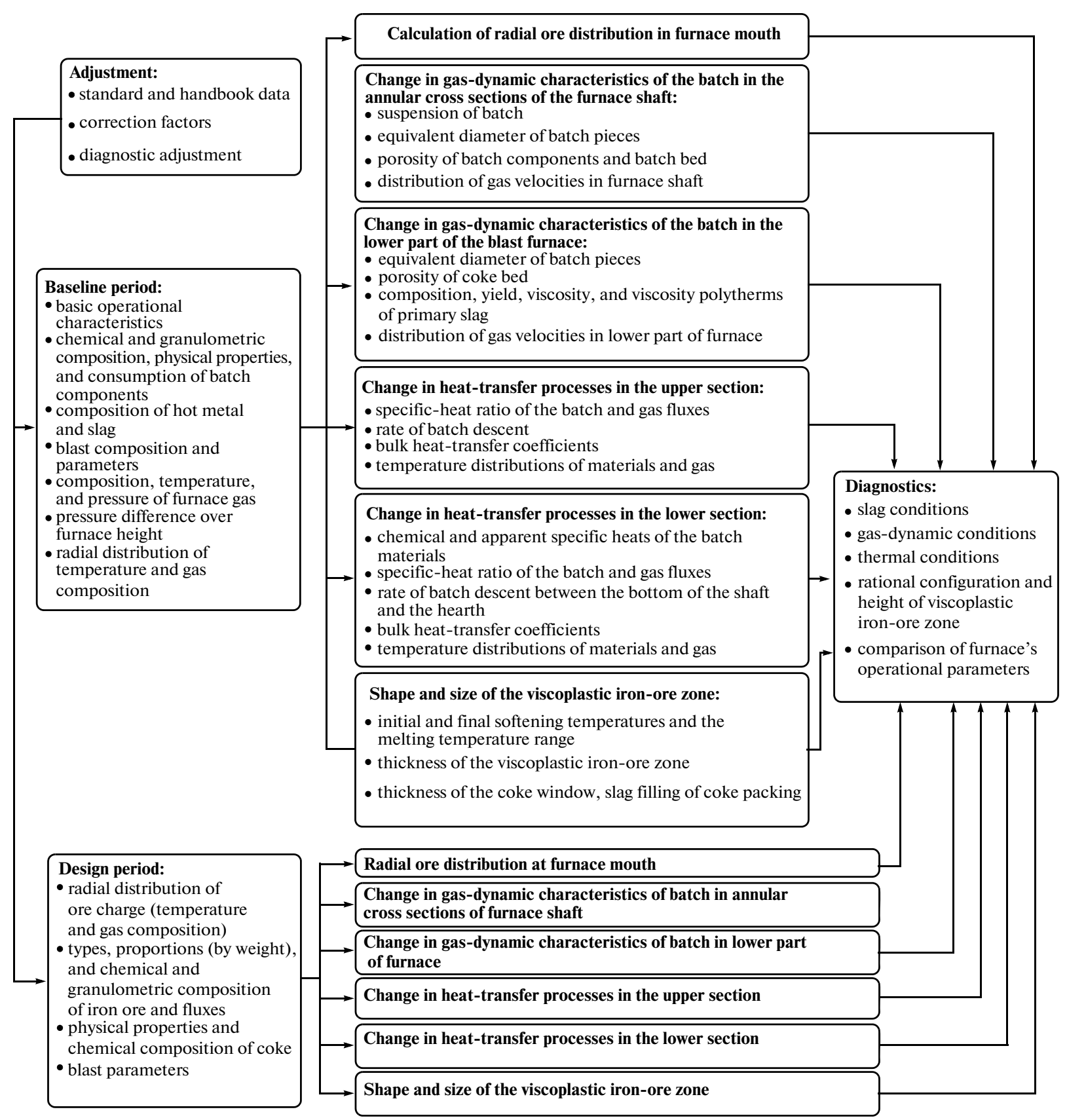

Fig. 2. Subsystem for modeling the viscoplastic iron-ore zone.

ing properties of the slag, the fractional composition of the coke, and the coke strength $\left(M_{25}\right.$, the hot strength, $M_{10}$, abrasion resistance, etc.).

(2) Calculation of all the parameters analogously to the baseline period, diagnostics of furnace operation, and change in the furnace productivity and coke consumption by means of correction factors.

The adjustment module, which includes subsystems for standard and handbook data and for diag- nostic adjustment, permits matching of the model to the specific operating conditions of the furnace.

The basic formulas for parameter calculation may be found in [15-18].

As an example, we now consider the application of the model to blast furnace 10 at OAO Magnitogorskii Metallurgicheskii Kombinat (MMK). The table presents the basic operational characteristics of the furnace. The iron-ore component of the batch includes 
Operational characteristics of blast furnace 10 at OAO MMK (baseline period)

\begin{tabular}{|c|c|}
\hline Characteristic & Value \\
\hline Hot-metal output, t/day & 4555 \\
\hline Consumption of dry skip coke, $\mathrm{kg} / \mathrm{t}$ of hot metal & 474 \\
\hline Consumption of iron ore, $\mathrm{kg} / \mathrm{t}$ of hot metal & 1656 \\
\hline Pellet content in iron ore, $\mathrm{kg} / \mathrm{kg}$ & 0.25 \\
\hline Blast parameters & \\
\hline flow rate, $\mathrm{m}^{3} / \mathrm{min}$ & 3450 \\
\hline pressure, atm & 2.8 \\
\hline temperature, ${ }^{\circ} \mathrm{C}$ & 1150 \\
\hline oxygen content, $\%$ & 28.42 \\
\hline natural-gas flow rate, $\mathrm{m}^{3} / \mathrm{t}$ of hot metal & 85.5 \\
\hline Parameters of blast-furnace gas & \\
\hline pressure, atm & 1.48 \\
\hline temperature, ${ }^{\circ} \mathrm{C}$ & 155 \\
\hline Gas composition, $\%$ & \\
\hline $\mathrm{CO}_{2}$ & 20.25 \\
\hline $\mathrm{CO}$ & 25.1 \\
\hline $\mathrm{H}_{2}$ & 7.59 \\
\hline Hot-metal composition, $\%$ & \\
\hline $\mathrm{Si}$ & 0.64 \\
\hline Mn & 0.34 \\
\hline S & 0.022 \\
\hline $\mathrm{C}$ & 4.74 \\
\hline Slag yield, $\mathrm{kg} / \mathrm{g}$ hot metal & 325 \\
\hline Slag composition, $\%$ & \\
\hline $\mathrm{CaO}$ & 35.02 \\
\hline $\mathrm{SiO}_{2}$ & 36.18 \\
\hline $\mathrm{Al}_{2} \mathrm{O}_{3}$ & 13.39 \\
\hline $\mathrm{MgO}$ & 9.82 \\
\hline $\mathrm{MnO}$ & 0.41 \\
\hline $\mathrm{FeO}$ & 0.22 \\
\hline
\end{tabular}

OAO MMK sinter and pellets from Sokolovsk enrichment facility, with the following chemical composition:

Element

Content, $\%$

in OAO MMK sinter in Sokolovsk pellets

$\begin{array}{lrr}\mathrm{Fe} & 56.970 & 63.080 \\ \mathrm{Mn} & 0.270 & 0.160 \\ \mathrm{~S} & 0.039 & 0.031 \\ \mathrm{P} & 0.027 & 0.013 \\ \mathrm{CaO} & 8.890 & 1.040 \\ \mathrm{SiO}_{2} & 6.070 & 5.100 \\ \mathrm{Al}_{2} \mathrm{O}_{3} & 2.020 & 1.700 \\ \mathrm{MgO} & 2.020 & 1.000 \\ \mathrm{FeO} & 12.060 & 3.730 \\ \mathrm{TiO}_{2} & 0.260 & 0.300\end{array}$

In Fig. 3, we show the radial distribution of the carbon-dioxide content and ore charge. In Fig. 4, we show the calculated position and configuration of the viscoplastic iron-ore zone.

The thickness of the cohesion zone varies from $2.04 \mathrm{~m}$ in the annular cross sections, with high ore load, to $3.09 \mathrm{~m}$ in the central part of the batch column. This large value may be attributed to the considerable melting range $\Delta t_{\mathrm{m}}=379^{\circ} \mathrm{C}$ of the ore. On account of the high fluidization temperature (corresponding to the appearance of fluid slag) $t_{\mathrm{fl}}=1477^{\circ} \mathrm{C}$, the lower boundary of the viscoplastic zone falls practically to the combustion zone. In this case, the formation of final slag, when ash from the burning coke reaches the slag melt leaving the viscoplastic zone, is confined to a limited zone over a small time interval. In the baseline period, the ore distribution corresponds to $\mathrm{W}$-shaped isotherms and viscoplastic zone (Fig. 1d). This is observed when moderately developed peripheral and central gas fluxes are established in the furnace. With a W-shaped viscoplastic zone, it is impossible to obtain high productivity and low coke consumption, and the refractory lining is damaged by the hot gases. The thickness of the coke windows in the bosh region is about $260 \mathrm{~mm}$ for furnace 10 . Only some of the coke windows are intact (about 4-5); the others hardly transmit any gas, since they do not have access to the furnace's working space.

As is evident from Fig. 5, the degree of batch suspension by the gas flux in the upper part of the furnace is $33.17 \%$ in the region of the ore crest and $44.18 \%$ in the central sections of the batch column, where there is minimal loose batch; the maximum permissible value is $55 \%[15,16]$. In the lower part of the furnace, likewise, the batch is not fluidized: the suspension of the batch by the gas flux is as much as $77.92 \%$, and only the presence of the upper layers of materials ensures a dense bed in the lower part of the furnace. The relatively low degree of suspension in the upper part of the furnace is due to the low gas flow rate (low blast flow rate) in the batch bed. This, in turn, is associated with the high gasdynamic drag of the viscoplastic zone (cohesion zone). Accordingly, in prediction, the parameter variation affecting the gas-dynamic drag in the lower part of the furnace is considered.

The viscoplastic zone at the bottom of the furnace determines the gas-dynamic behavior, as also indicated by calculations of the degree of batch suspension by gas in annular cross sections for the bottom and top of the furnace column (Fig. 5).

As an example, consider the size of the cohesion zone in smelting solely on the basis of OAO MMK sinter, with the elimination of ore pellets. This case is adopted simply to show the influence of the characteristics on the size of the viscoplastic zone. We disregard the associated decrease in iron content in the batch, the unavoidable correction of the batch composition so as to maintain the slag basicity, and other compli- 

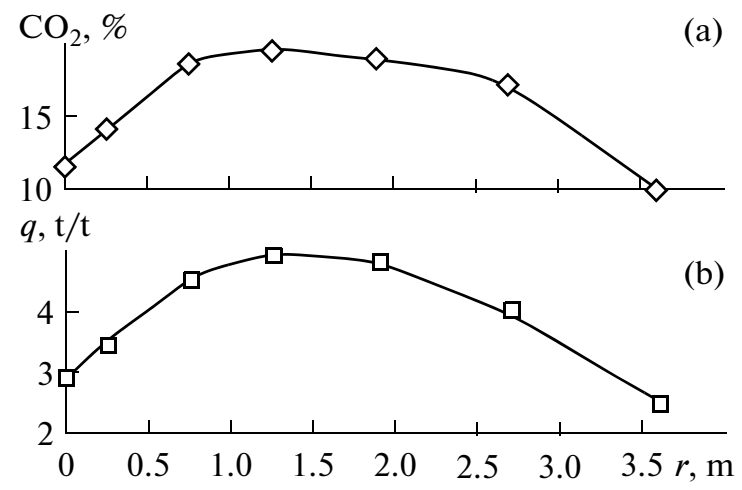

Fig. 3. Radial distribution of the carbon-dioxide content (a) and ore charge $q$ (b) at OAO MMK blast furnace 10 .

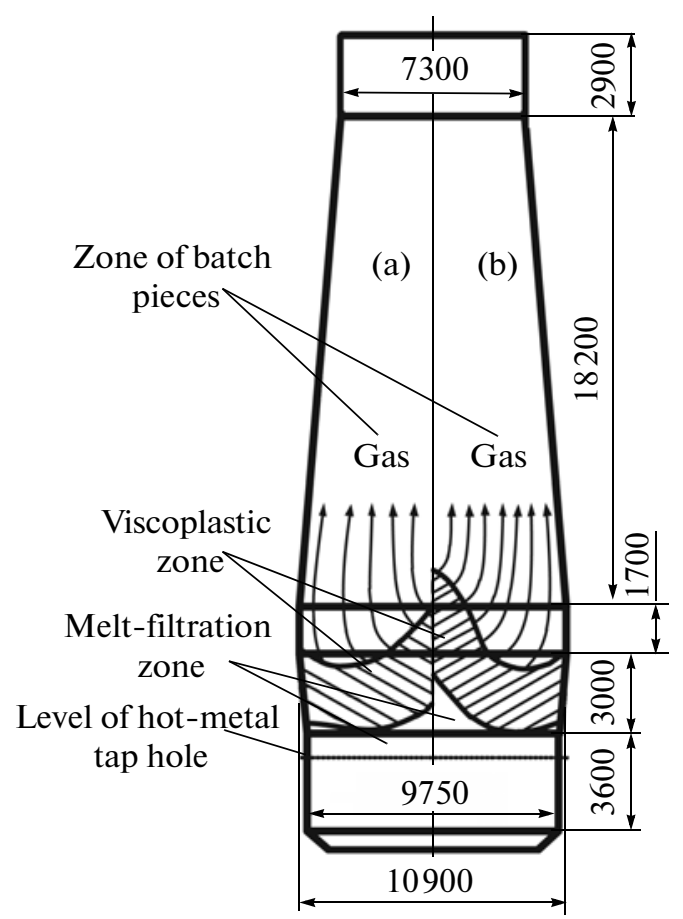

Fig. 4. Position of viscoplastic zone in OAO MMK blast furnace 10 with different gas distributions: (a) with the radial variation in the $\mathrm{CO}_{2}$ content assumed in the baseline period; (b) with the predicted variation in ore charge.

cating factors. Likewise, the other furnace parameters are not corrected; that is, they remain the same as in the baseline period. In Fig. 6, the shape and position of the viscoplastic zone are compared for the baseline case (OAO MMK sinter + Sokolovsk pellets) and the prediction period (only OAO MMK sinter). As shown by the calculations, the blast flow rate may be increased by $30 \%$ relative to the baseline case.

In Fig. 7, we show the radial distribution of the $\mathrm{CO}_{2}$ content and ore load with development of the axial gas flow in the prediction period. With moderately developed peripheral and axial motion of the gas flow with

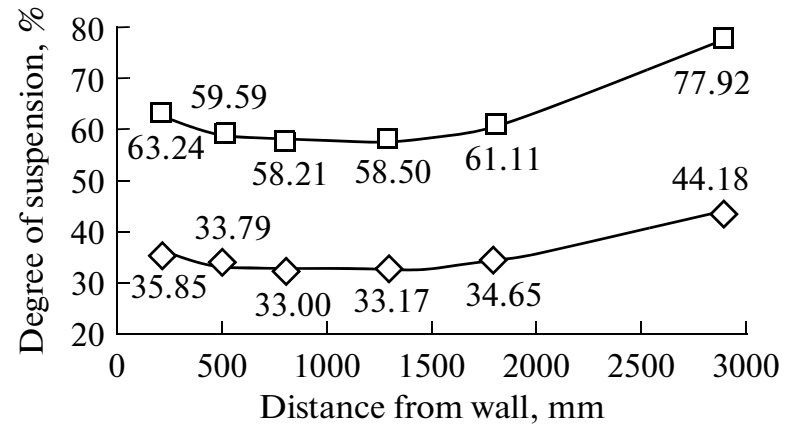

Fig. 5. Distribution of the degree of batch suspension by the gas in the annular cross sections: $(\square)$ bottom of furnace; $(\diamond)$ top of furnace.

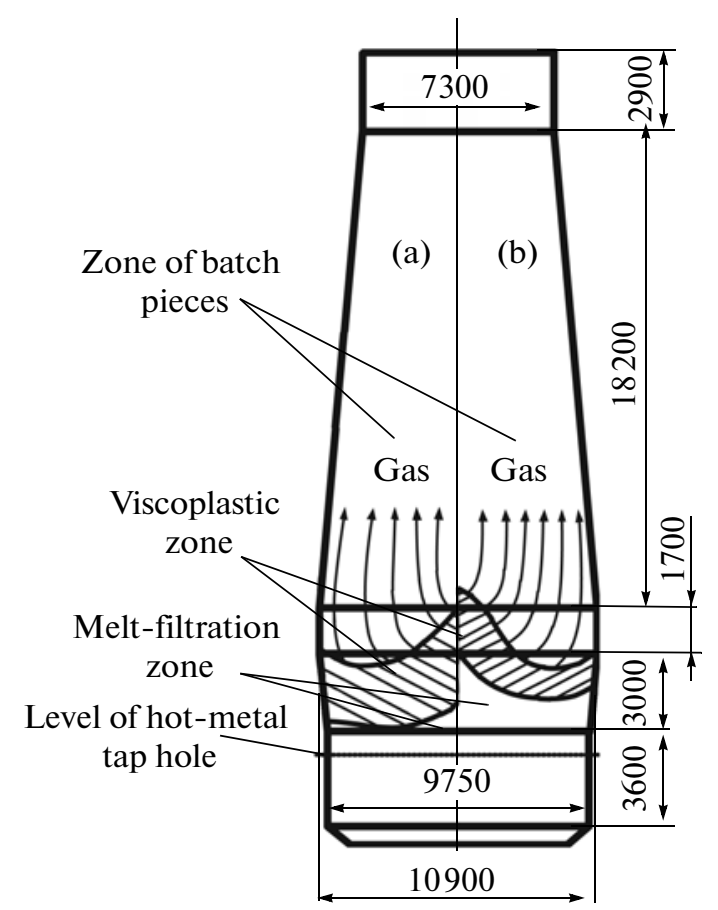

Fig. 6. Shape and size of viscoplastic zone in blast furnace 10 when the batch consists of OAO MMK sinter + Sokolovsk pellets (a) and solely of OAO MMK sinter (b).

a gas distribution corresponding to opening of the central zone of the furnace, we find that the viscoplastic zone is shifted upward in the central region and descends somewhat in the outer regions with a large ore load. This is clearly evident in Fig. 4b.

With an axial gas flow, when the viscoplastic zone rises in the central region, an additional section for gas penetration into the viscoplastic zone is formed: the gas may move from the lower zone (the melt-filtration zone) through coke windows to the zone of batch and gas fluxes (indicated by arrows). Calculations show that increasing the number of coke windows increases 

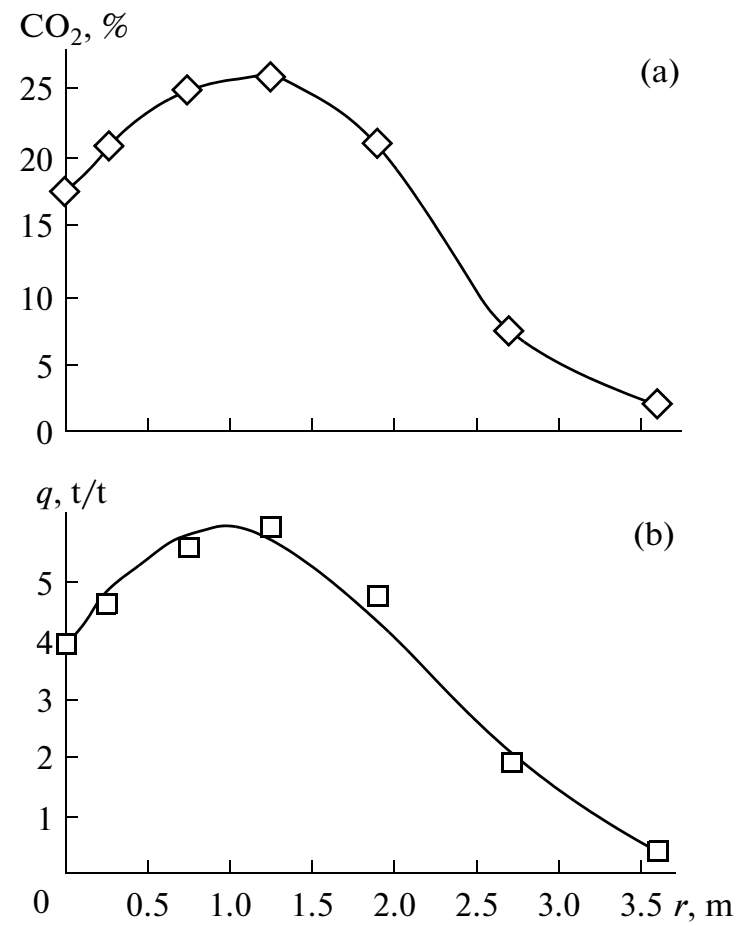

Fig. 7. Radial distribution of the carbon-dioxide content (a) and ore charge $q$ (b) at OAO MMK blast furnace 10 in the prediction period.

the blast flow rate in the prediction period, with the same degree of batch suspension by the gas as in the baseline period. Hence, furnace productivity is increased by $5.4 \%$.

\section{CONCLUSIONS}

The proposed mathematical model permits assessment of the position and shape of the viscoplastic iron-ore zone (cohesion zone) in a blast furnace on the basis of readily available information regarding the blast furnace in the baseline period. Identification of a rational configuration for this zone is also possible. In addition, the model permits the solution of design problems with variation in the furnace parameters.

\section{REFERENCES}

1. Yusfin, Yu.S., Metallurgiya chuguna (Metallurgy of Iron), Moscow: IKTs Akademkniga, 2004.

2. Blast Furnace Phenomena and Modeling, Omori, Y., Ed., New York: Elsevier, 1987.
3. Vegman, E.F., Domennoe proizvodstvo: Spravochnoe izdanie. T. 1. Podgotovka rud i domennyi protsess (BlastFurnace Production: A Handbook, Vol. 1: Ore Preparation and Blast-Furnace Processes), Moscow: Metallurgiya, 1989.

4. Inada, S., Kabayashi, I., and Isabe, M., Tetsu to Hagane, 1984, vol. 34, no. 4, pp. 59-64.

5. Hatiga, S., Ono, R., Fuse, K., et al., Tetsu to Hagane, 1986, vol. 36, no. 3, pp. 77-80.

6. Vecehida, G. and Giuli, M., Rev. Metall.-CIT, 1984, vol. 81 , no. 5 , pp. $369-383$.

7. Peters, K.H., Alpeter, W., Bachhofen, H.Y., et al., Stahl Eisen, 1984, vol. 104, no. 14, pp. 59-62.

8. Yamamoto, T., Shokyu, T., Kanoshima, H., et al., Trans. Iron Steel Inst. Japan, 1982, no. 10, p. 774.

9. Ohno, Y., Kondo, K., and Fukushima, T., Rev. Metall.CIT, 1983, no. 10, pp. 809-825.

10. Kyle, I., Conference Proceedings (September 11-13, 1979), London, 1980, pp. 403-415.

11. Tovarovskii, I.G., Bol'shakov, V.I., and Merkulov, A.E., Analiticheskie issledovaniya domennoi plavki (Analytical Investigation of Blast-Furnace Smelting), Dnepropetrovsk: ChMP Ekonomika, 2011.

12. Murav'eva, I.G., Semenov, Yu.S., and Gladkov, N.A., Chern. Metall.: Byull. Inst. Chermetinformatsiya, 2011, no. 8, pp. 38-44.

13. Dobroskok, V.A., Kuznetov, N.A., and Tumanov, A.I., Izv. Vyssh. Uchebn. Zaved., Chern. Metall., 1985, no. 3, pp. 145, 146.

14. Emel'yanov, S.V., Korovin, S.K., Myshlyaev, L.P., et al., Teoriya i praktika prognozirovaniya $v$ sistemakh upravleniya (Theory and Practice of Prediction in Control Systems), Moscow: Izd. Ob'edinenie Rossiiskie Universitety, 2008.

15. Onorin, O.P., Spirin, N.A., Terent'ev, V.L., et al., Kompyuternye metody modelirovaniya domennogo protsessa (Computer Modeling of Blast-Furnace Processes), Yekaterinburg: Izd. UGTU-UPI, 2005.

16. Spirin, N.A., Lavrov, V.V., Rybolovlev, V.Yu., et al., Model'nye sistemy podderzhki prinyatiya reshenii $v$ ASU TP domennoi plavki (Model Systems for Decisionmaking Support in Automatic Blast-Furnace Control Systems), Yekaterinburg: Izd. UrFU, 2011.

17. Kitaev, B.I., Yaroshenko, Yu.G., and Lazarev, B.D., Teploobmen $v$ domennoi pechi (Heat Transfer in Blast Furnaces), Moscow: Metallurgiya, 1966.

18. Spirin, N.A., Ovchinnikov, Yu.N., Shvydkii, V.S., and Yaroshenko, Yu.G., Teploobmen i povyshenie effektivnosti dommenoi plavki (Heat Transfer and Improved Blast-Furnace Efficiency), Yekaterinburg: Izd. UGTU-UPI, 1995.

Translated by Bernard Gilbert 